ISSN: 1887-2417

ISSN-e: $2386-4362$

DOI: $10.17979 / a m s .2017 .23$ 24.0.3382

\title{
Programa Ecológico de Guimarães para a Aprendizagem do Desenvolvimento Ambiental Sustentável-PEGADAS
}

Guimarães Ecological Program for the Learning of Sustainable Environmental Development-PEGADAS

Patrícia Ferreira ${ }^{1}$, Jorge Cristino ${ }^{1}$ e Carlos Ribeiro². 1. Câmara Municipal de Guimarães. 2. Laboratório da Paisagem de Guimarães (Portugal).

\begin{abstract}
Resumo
Inserido no âmbito de um projeto municipal mais amplo que visa o desenvolvimento sustentável do território, o programa PEGADAS - Programa Ecológico de Guimarães para - Desenvolvimento Ambiental Sustentável pretendeu reforçar a educação e sensibilização ambiental num contexto de promoção dos objetivos mundiais consagrados na Agenda 2030 e que impõe como objetivo essencial a garantia da aquisição de "conhecimento e habilidades necessárias para promover o desenvolvimento sustentável por meio da educação para o desenvolvimento sustentável e estilos de vida sustentáveis", ao mesmo tempo que coloca como prioritários os eixos da proteção ambiental, através do uso de energias renováveis, ação contra as alterações climáticas, proteção da vida marinha e terrestre, produção e consumos sustentáveis ou desenvolvimento de comunidades sustentáveis (Centro Regional das Nações Unidas para a Europa Ocidental, 2016). Tem como princípios a equidade, a transversalidade e a abrangência de ação nas suas interações com as escolas em particular e a comunidade alargada no geral.
\end{abstract}

\section{Astract}

As part of a broader municipal project aimed at sustainable development of the territory, the PEGADAS program-Ecological Program for Sustainable Environmental Development of Guimarães aimed to reinforce education and environmental awareness in a context of promoting the global objectives enshrined in Agenda 2030. The main goal is to guarantee the acquisition of "knowledge and skills necessary to promote sustainable development through education for sustainable development and sustainable lifestyles". At the same time PEGADAS assume as priority the environmental protection, through the use of renewable energy, action against climate change, the protection of marine and terrestrial life, the sustainability of production and consumption and the development of sustainable communities (United Nations Regional Center for Western Europe, 2016). Its principles are equity, transversality and scope of action in its interactions with schools in particular and the community in general.

\section{Palavras-Chave}

Educação; Sustentabilidade; Sensibilização; Transversalidade; Desenvolvimento.

\section{Key Words}

Education; Sustainability; Awareness; Transversality; Development 
A Educação Ambiental é hoje assumidamente um dos pilares fundamentais de uma estratégia que vise o desenvolvimento sustentável de um território e a alteração de alguns paradigmas e comportamentos, a prova disso é a recente apresentação da Estratégia Nacional de Educação Ambiental 2020 que aponta como "crescente a importância da atuação dos técnicos, tanto das autarquias como dos equipamentos de educação ambiental no desenvolvimento de projetos ou programas de Educação Ambiental", reconhecendo já a "existência na grande maioria dos municípios de profissionais ligados aos pelouros de Ambiente e Educação com competências técnicas específicas que promovem já um conjunto de atividades nesta área" (RePúblicA PoRTUGUESA, 2016). Também já anteriormente a Agenda 2020, tinha estabelecido metas ambiciosas para redução de $20 \%$ de emissões de gases, incremento do uso de energias renováveis em $20 \%$, ou mesmo redução de $20 \%$ do consumo energético, metas consubstanciadas nos programas Europa 2020 e Portugal 2020.

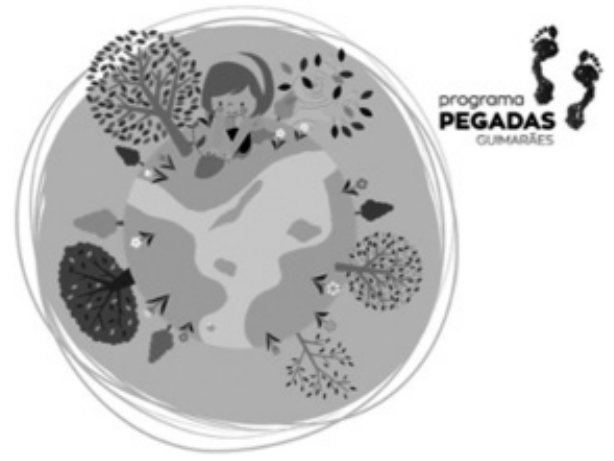

Figura 1: Programa de Educação AmbientalPEGADAS

\section{Princípios Orientadores}

A criação do programa ambiental PEGADAS teve como objetivos principais tornar-se num projeto transversal em temáticas para o ambiente e sustentabilidade, sendo inclusivo e abrangente pelas parcerias criadas através de outros programas conexos, como o caso do programa EcoEscolas; agregador e impulsionador de comportamentos e práticas ecológicas. $O$ PEGADAS assume ainda um carácter inclusivo e transgeracional, não pretendendo ter apenas como alvo as escolas, mas também as IPSS, permitindo o envolvimento dos seniores através de um conjunto de atividades para os " +65 ", contribuindo deste modo para um envelhecimento ativo e utilizando a partilha de conhecimento entre gerações para o desenvolvimento de ações de caráter de educação ambiental. A implicação direta das famílias na realização de atividades traduz-se na abrangência dos resultados comunitários.

Guimarães tem aliás assumido como primordial o desenvolvimento sustentável, através de estratégias integradas e concertadas, como atesta o enfoque na criação de novos espaços verdes no concelho, da criação da Horta Pedagógica, agora rede Municipal de Hortas Comunitárias, bem como o investimento pioneiro na investigação e desenvolvimento na área da sustentabilidade através de fundos municipais e parcerias com as Universidades 
do Minho e de Trás-os-Montes e Alto Douro ou como projetos vários integrados no plano estratégico para o desenvolvimento sustentável - Guimarães mais Verde - e que servirá de base para a Candidatura de Guimarães a Capital Verde Europeia 2020.

\section{Operacionalização}

Desenhado com um conjunto alargado de atividades (mais de cem atividades), através da aglutinação de mais de trinta parceiros em seis áreas temáticas distintas (resíduos, energia, natureza/biodiversidade, água, agricultura e mobilidade), o programa PEGADAS direciona-se a todas as escolas do concelho, sendo coordenado e gerido pelo Laboratório da Paisagem de Guimarães.

A particularidade desta gestão, num centro de Investigação e Desenvolvimento, permite igualmente contribuir de forma pioneira para a divulgação de ciência e investigação científica, permitindo maior proximidade aos trabalhos de investigação nestas áreas.

Contudo, o PEGADAS não pretende apenas disponibilizar um plano de atividades às instituições, mas também assumir-se como um programa flexível e dinâmico que possibilite às escolas o desafio aos parceiros para a realização de atividades diversas por estas desenhadas, contando com as ideias e os contributos de todos para melhorar o desenho e a sua articulação. De igual modo, o plano de atividades delineado obedece ainda a critérios de articulação com as diferentes áreas curriculares, podendo assim constituir-se como ferramenta adicional ao trabalho de aprofundamento realizado em contexto de sala de aula ao nível da aprendizagem.

De forma a tornar mais eficaz a coordenação e implementação das ações disponibilizadas pelo programa, o PEGADAS solicita a indicação de um coordenador PEGADAS, por estabelecimento de ensino, com o qual é realizado o contacto direto e que permite a adaptação do trabalho desenvolvido às especificidades do contexto de cada uma das escolas.

O PEGADAS permite prover a cada estabelecimento de ensino um leque de atividades, sem que para isso tenha sido obrigado a um reforço orçamental, propondo-se a fazer mais e melhor pela rentabilização dos recursos e projetos existentes.

\section{Ações Âncora}

Atendendo à dimensão e significância de alguns temas abordados neste programa, bem como à sua coadunação com objetivos e estratégias específicas do Plano de Ação Municipal para a área do Ambiente e Sustentabilidade, algumas das atividades 
assumem um caráter chave para o trabaIho desenvolvido ao nível da educação e sensibilização ambiental. Estas ações são consideradas primordiais no trabalho a desenvolver pelas escolas, potenciando maior abrangência do seu impacto na comunidade escolar e, subsequentemente na comunidade alargada. Este conjunto de atividades pressupõe a sua assunção em todos os estabelecimentos de ensino de acordo com as suas próprias especificidades. Destas destacam-se algumas das presentes neste vasto programa de educação ambiental:

- Programa Eco-Escolas: Incentivo às escolas do concelho à inscrição no Programa Internacional Eco-Escolas;

- Eco Parlamento: Assente nos princípios de Democracia Participativa Jovem, visa atrair os jovens para o debate municipal, refletindo sobre o desenvolvimento sustentável da cidade de Guimarães;

- Guimarães Mais Floresta: projeto tem como objetivo primordial alertar para a importância da preservação da floresta, promovendo maior consciencialização deste tema nos jovens e na comunidade, bem como o seu envolvimento na proteção deste ecossistema. O resultado desta atividade será traduzido na plantação de 15 a 20 mil novas árvores autóctones;

- Projeto Rios: Considerando a estratégia municipal e o Plano de Despoluição para o Rio Ave, esta ação, articulada com a
ASPEA-Associação Portuguesa de Educação Ambiental, visa a adoção e monitorização de troços de rio, com o intuito de promover a sensibilização da sociedade civil, através da comunidade escolar, para os problemas, necessidades de proteção e valorização dos sistemas ribeirinhos. Neste âmbito, o Laboratório da Paisagem tem em desenvolvimento um projeto científico de monitorização da qualidade da água e estado ecológico das linhas de água possibilitando não só a identificação de focos de poluição como a sugestão de medidas interventivas que contribuam para a melhoria do estado ecológico das linhas de água;

- Brigadas do Ambiente: Criação de brigadas para a interpretação, monitorização e preservação dos recursos naturais, ecossistemas e equipamentos urbanos existentes nas proximidades das escolas e no próprio espaço escolar;

- Biodiversity GO!: criação de uma base de dados da biodiversidade de Guimarães.

Não menos relevantes, apontam-se agora algumas das ações complementares do PEGADAS:

- EducaBicla: promotor do transporte ciclável;

- Teatro Bus: apresentação de uma peça de teatro itinerante "A Viagem", versando as questões ambientais, e que é levada às escolas no autocarro Teatro Bus, local onde a peça decorre ou o 
- Café com Ambiente: Tertúlias mensais de carácter informal, versando temas diversos no âmbito da sustentabilidade ambiental.

\section{Balanço dos Resultados}

Ao longo do primeiro ano foram organizadas 193 atividades distintas, das quais resultaram 579 ações na totalidade das escolas concelho (95), e o envolvimento de 19.227 alunos e 1.780 professores, com a colaboração de 39 parceiros. A concretização do programa levou ainda ao incremento em cerca de $40 \%$ do número de escolas inscritas no programa da Eco-Es-

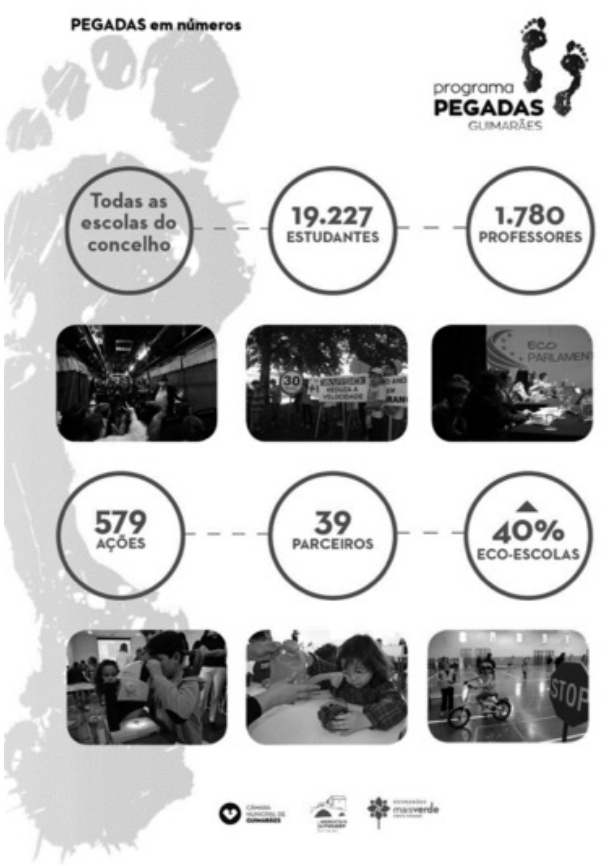

Figura 2: Balanço do primeiro ano de implementação do programa PEGADAS em Guimarães. colas da $A B A E$, o que demonstra o compromisso de toda a comunidade educativa pelas temáticas da sustentabilidade.

Estes números, acompanhados dos indicadores de avaliação do programa (relatórios das escolas e entidades promotoras, comunicações orais em congressos nacionais e internacionais) permitem atestar do sucesso desta iniciativa. O PEGADAS foi ainda considerado exemplo de boas práticas pela $A B A E$ e reconhecido como amigo do Ano Internacional para o Entendimento Global (IYGU), sendo que uma das suas iniciativas, "Eco Parlamento", foi apontada como medida exemplar, pela forma como através do princípio da Democracia Participativa Jovem, atraiu jovens para o debate concelhio sobre o desenvolvimento sustentável para o território.

\section{Referências bibliográficas}

CENTRO DE INFORMAÇÃO REGIONAL DAS NAÇÕES UNIDAS PARA A EUROPA OCIDENTAL (2016). Guia sobre o Desenvolvimento Sustentável - 17 Objetivos para Transformar o Nosso Mundo, em http://www.unric.org/pt/images/ stories/2016/ods_2edicao_web_pages.pdf LABORATÓRIO DA PAISAGEM (2016), Sítio Oficial, em http://www.labpaisagem.pt/pegadas/ REPÚBLICA PORTUGUESA (2016). Estratégia Nacional de Educação Ambiental - Caminho para uma Estratégia de Educação Ambiental, em https://www.apambiente.pt/_zdata/DESTAQUES/2016/ENEA_final.pdf 